RUNNING HEAD: Smoking representations

A Q-methodological investigation into the meanings of cigarette consumption

Timothy P Moss ${ }^{1}$ and Emma Bould ${ }^{2}$

${ }^{1}$ School of Psychology, University of the West of England (Bristol), UK

${ }^{2}$ Psychology Department, Lancaster University, UK

$\begin{array}{ll}\text { Author Correspondence: } & \text { Timothy Moss } \\ & \text { School of Psychology } \square \\ & \text { University of the West of England } \square \\ & \text { Coldharbour Lane } \square \\ & \text { Bristol } \square \\ & \text { BS16 1QY } \\ \text { Tel: }+44(0) 1173282189 \\ \text { Fax: }+44(0) 1173282904 \\ \text { Email: tim.moss@ @we.ac.uk }\end{array}$

WORD COUNT: 7969

COMPETING INTERESTS: None

KEY WORDS: smoking, social representation, q-methodology

\title{
BIO-BIBLIOGRAPHICAL NOTES:
}

Dr Tim Moss is principal lecturer in health psychology and subject group leader for health psychology at the University of the West of England (Bristol). His interests include public health applications of psychology, and the psychology of disfigurement and visible difference.

Dr Emma Bould is a research associate at the University of Lancaster, with interests in applied aspects of psychology theory. Her previous work has been in the areas of disability and emotional expression. 


\begin{abstract}
A Q-methodological design was used to identify shared subjective explanations of smoking amongst never smokers, current smokers, and ex-smokers, and to consider whether some discourses were protective or facilitated quitting. Four factors were selected and given the (simplified) names of independent addict, independent non-addict, anti-smoker, and social addict. The first two factors were dominated by current and exsmokers, and the last two by never-smokers. Important differences emerged on the use of the 'addiction' concept, the use of smoking as a tool for affect management, the role of image manipulation, and the general positive and negative perceptions of smoking. The functional use of the different discourses is discussed, as are the implications for health promotion and understanding the problem of smoking.
\end{abstract}




\section{INTRODUCTION}

Smoking kills 120,000 people in the UK every year (Department of Health, 1998).

Although, it is a major public health issues, and has been the focus of countless interventions and studies, the literature investigating smoking has largely concentrated on objective predictors of initiation or maintenance - for example, personality factors or biological pre-disposition. What has received less attention are the accounts and explanations that smokers themselves give as to their smoking behaviour. It is central to this paper that to effectively engage with smokers, we must understand the subjective explanations, and move beyond individuals' accounts of smoking to investigate the shared, social representations. Moscovici (1976) described the process by which shared subjective meaning is created through the interplay of individuals and social groups, arguing that the existence of social groups is based upon a shared social representation. Moscovici's ideas are relevant to the problem of smoking, as in order to understand initiation and maintenance of smoking, it is necessary to understand the diversity of shared subjective meanings that exist amongst smokers, never-smokers and ex-smokers.

The aim of this paper is to identify the structure of these social representations, their content, and the relationships between them. This will allow a critical approach to be taken to the health promotion related to smoking, and a consideration of appropriate types of intervention. To do this, themes that exist in the literature will be identified. These themes themselves are not social representations (although they do form part of their content), and whilst the existing literature treats them in isolation (as free-floating ideas), this paper will endeavour to work with discourses around these themes to facilitate sophisticated theorisation. 
Themes in Subjective Meanings

\section{Coping and Respite in Demanding Social Circumstances}

Breteler et al. (1996) conceptualised smoking from the perspective of transactional models of stress and coping and argued that smoking is best seen as a coping behaviour in the face of stress and low self-efficacy. This relatively abstract and theoretical point of view is given credibility by qualitative investigations (e.g. Graham, 1987; Stewart et al. 1996), which place the idea of coping in a clearer social context - that of social disadvantage. Graham noted that not only were working class women more likely to smoke than middle class women, but these differences were exaggerated if the women were also carers. Smoking may be a means of structuring caring, and re-imposing structure when it breaks down, and as such, viewed as a 'necessary luxury'. Over and above any pharmacological effects that may change mood directly, the cigarette has a complex symbolic representation to working class women that facilitates their daily living in adverse circumstances.

\section{Situational Factors Influencing Smoking}

A number of studies found smoking is associated with the smoker being in a specific context (e.g. a pub). It is possible to explain this in behaviourist, classical conditioning terms, as the meaning of smoking differs in different situations (Chamberlain \& O'Neill, 1998), alongside the availability of cigarettes and offers of cigarettes (e.g. Moffat \& Johnson, 2001; Seguire \& Chambers, 2000).

\section{The Role of Peers and Friends}

The role of peers is rather more complex than lay explanations of 'peer pressure'. It is certainly true that if a person's friend smokes, they are also more likely to smoke 
themselves (Mayhew, 2000), particularly if there is peer approval of smoking (Morgan \& Grube, 1989; Unger, 2001). One function of cigarette smoking is to facilitate entry into a peer group (Gilliard \& Bruchton-Schweitzer 2001; Wiltshire, Amos, Haw \& McNeill, 2005).

Michel and Amos (1997) found clear associations between hierarchical social networks and smoking. In their study of Scottish teenagers, the 'top girls' (as perceived by all aspects of the cohort) had higher self-esteem, and were described (by peers) as 'good looking . . having all the gear ... dead popular' (p. 1864). They were also more likely to smoke than 'middle girls' who were more academic, and described as 'sensible. . .quiet ... friendly' (p. 1865). The notion of systematic pressure and coercion to smoke cigarettes is becoming increasingly rejected by smokers and smoking researchers, and Stewart-Knox et al. (2005) have argued there is little objective evidence of 'pressure' being applied in most cases of smoking initiation.

\section{Normalisation}

Smoking is reported by smokers as normal and not deviant (e.g. Unger et al. 2001), positioning the smoker as someone who does not particularly have to account for their actions.

\section{Addiction}

When exploring the social meanings of smoking, substance users tend to talk about their cigarette addiction on an individual and shared social level. Gillies and Willig (1997) used discourse analysis to analyse women's accounts of smoking, and found the discourse of addiction could be divided into physiological and psychological accounts. The physiological discourse draws strongly on 'scientific' language (“you get the nicotine and 
that in your blood", "[nicotine] goes straight into the bloodstream and goes to the brain", p. 291). This scientific, external discourse serves to distance the speakers from responsibility for their addiction, and attempts to give their accounts authority. Gillies and Willig also argue that it serves to distance the self (the speaker) from the effects of smoking and responsibility for the addiction. This effect has been particularly noted in adolescents (Amos, Wiltshire, Haw \& McNeill, 2006)

\section{Locus of control}

Within psychology generally, and particularly within health psychology, the notion of Locus of Control (loc) (Rotter, 1966) has remained popular. At its outset, the theory proposed that individuals have a generalised tendency to view the source of environmental reinforcement as either internal or external. Internal loc individuals believe that success comes through their own actions and efforts; external loc is associated with a belief that fate, luck and other people (not under their control) determine events. The theory has been specifically applied to smoking (Georgiou \& Bradley, 1992). It is worthwhile, however, noting that validated items from the scale - and by implication, the meanings of smoking as an activity - did differentiate smokers and never-smokers - for example, "if I fail to quit smoking, I wasn't meant to be a never-smoker" reflects an external locus of control (a belief in fate) which is related to reduced intention to give up smoking and more smoking behaviour.

\section{Mood manipulation}

A persistent theme in the smoking literature is that of affect control through smoking. Smokers have provided accounts of various mood changes sought or induced by smoking, and researchers have attempted to demonstrate the veracity of these accounts. Being 
depressed (Clayton, 1991), stress reduction and stress management (e.g. Denscombe, 2001b), relaxation (e.g. Gilliard \& Bruchon-Schweiter, 2001), relief of boredom (e.g. Moffat \& Johnson, 2001), and other specific emotional states, for example anger, being bothered, feeling ill at ease, and out of control (e.g. Seguire \& Chalmers, 2000) have all been associated with initiating or maintaining smoking. This evidence suggests that for many smokers, there seem clear utilitarian reason for smoking, as a means of regulating affect.

\section{Health beliefs}

The belief that smoking is hazardous to health is a given in health and medical circles, but the perception of subjective risk is less clear. On one hand, studies show smokers understand that smoking provides a clear risk to their health (e.g. Chamberlain \& O'Neill, 1998; Clayton, 1991), and health concerns have been implicated as one of the main reasons why smokers quit (e.g. Brown, 1996; Stewart, 1999). There also tends to be an acceptance of the notion that passive smoking harms non-smokers (Glantz \& Jamieson, 2000). However, either cognitively or discursively, smokers also act to minimise the perceived threat to themselves (Moffat \& Johnson, 2000), even claiming a sense of personal invulnerability (Chamberlain \& O’Neill, 1998; Denscombe, 2001b). It is argued that there is not necessarily a great deal of benefit in quitting (Chamberlain \& O'Neill, 1998). This paradoxical perspective is perhaps explained by the ability of smokers to dissociate their own risk from a more generalised risk (cf. for example, Lyna et al. 2002).

\section{Positive smoking beliefs}

In addition to the vicarious positive functions that smoking is believed to confer on smokers, there are a number of direct positive consequences of smoking that have been 
reported. Gilliard and Bruchan-Schweiter's (2001) smoking scale identified such benefits as pleasure on lighting and handling cigarettes, enjoying watching smoke, and taking direct pleasure from the act of smoking. Similar benefits have also been reported by Denscombe (2001a), Mayhew et al. (2000), Moffatt and Johnson (2001) and McKie, Laurier, Taylor and Lennox (2003).

\section{Weight control}

Reducing appetite and weight control is one of the reasons that adolescent girls/young woman, in particular, start and continue to smoke. This account of female smoking has been consistently demonstrated, with Austin and Gortmaker (2001) and Boles and Johnson (2001) reporting that girls who are either over/underweight, dieting, or have lower resistance to pressure around gendered ideals (Fiisell \& Lafreniere, 2006; Zucker, Stewart, Pomerleau \& Boyd, 2005) are more likely to smoke.

\section{Family}

There is an extensive literature on the relationship between family smoking and initiation and maintenance of smoking amongst family members. Clayton (1991) reviewed the research and found that if either parent smoked (but particularly the same sex parent), or if siblings smoked, there is an increased likelihood of smoking. Furthermore, poor parental attachment, poor supervision, and low levels of parental concern are all related to smoking, as are unsupportive parents and non-participative parenting styles. Much of this work is focussed around the family as an objective predictor of smoking, so it is not yet clear the extent to which these factors are woven into subjective accounts of smoking. 


\section{Image Projection}

A great deal of work has gone into investigating the imagery associated with smoking the way in which cigarettes can act as a prop for the image projection of the smoker. For example, to look 'cool' has been most often suggested (e.g. Denscombe, 2001b; Lennon, Galloise, Owen \& McDermott, 2005; Seguire \& Chalmers, 2000). Looking 'hard' or 'tough' closely follows coolness in frequency (e.g. Denscombe, 2001b). The use of cigarettes as a symbol of transition into adulthood has also been reported (e.g. Denscombe, 2001b; Rugkasa et al. 2001; Seguire \& Chalmers, 2000).

\section{A Social Constructionist Approach}

The perspective in this work is essentially social constructionist. This label covers a panoply of methods and methodologies, but there are fundamental features. The first is that knowledge is a product of social negotiation, imbued with meaning arising from their social context. That is, what is 'known' in science or elsewhere, is not a revelation of some underlying reality, it is a culturally specific and an historically bounded representation. The second point is that these socially negotiated meanings exist linguistically, and are exposed linguistically. When we use language to describe social acts there is more than a literal identity between words and dictionary definitional meanings. Language carries with it surplus meaning of metaphor, and serves its own social functions. For example, in the nineteenth century, it was 'known' that tuberculosis was an illness which has not only fatal, but romantic consequences. To say 'I think I may be weakening with consumption [TB]' carried a quite different meaning than 'I think I may have smallpox'. The former disease carried connotations of worthy, poetic suffering - the latter simply an unpleasant and common way to die (see Sontag, 1977, 1989). The 
third fundamental point about social constructionist explanations is the notion that when individuals provide an explanation or account, it does not represent a single inherent opinion. Producing differing, multiple accounts is a means by which individuals create structure and meaning in a complex social world, and will be a product of context and audience. In the context of smoking, it has been shown that individuals are comfortable holding contradictory beliefs about the dangers of smoking, depending on whether it is them themselves, or a generalised other, whose danger is being assessed (Allbutt et el. 1995).

Too often, social constructionist studies do not analyse the behavioural consequences of the discourse described. This is a premature ending to such work. Access to, and use of particular discourses can limit and facilitate particular behaviours. For example, Holloway's (1989) analysis of discourse around the male sex drive demonstrated how particular discourses serve to legitimate particular behaviours as being biologically driven and inevitable, positioning men as aggressive sexual predators. In this study, the same argument is applied to smoking. It is anticipated that in the future, smoking will be seen as an anachronism, a behaviour that cannot be easily understood, as the discourse that permits initiation and maintenance of smoking will have become, in Gleeson's (1991) terms, a cultural artefact. In other words, it will not be within people's linguistic repertoire to justify and excuse smoking.

Choice and Rationale for the Methodology There is a clear and well-established history of using correlation methods to investigate supposed underlying traits, personality factors, beliefs, and attitudes. However, it can be argued that such traditional approaches are overtly positivist, assuming an ontological basis for the underlying factors that cannot be philosophically justified. Critics have also 
argued that these approaches reify pre-existing positions held by researchers, and that they are reductionist and individualising. Stephenson (1935) proposed an alternative method, Q-methodology, in which individuals' self-referent views (rather than test items within psychometric scales) were factor analysed. The basic approach is that statements about the topic of interest are rank ordered by individuals, and then factor analysed by person, rather than by statement. In this way, the perspectives (factors) that are identified are not the product of the researchers pre-suppositions, but emerge from the subjective understandings of the participants themselves so the work does not result in the reification of predefined constructs. It is the product of collective and shared social representations. Consequently, this study will employ Q-methodology to investigate the shared subjective meanings of cigarette smoking, and to essentially explore the diversity in representation of smoking amongst never-smokers, ex-smokers, and current smokers. It is argued that access to particular smoking discourses, will serve to legitimise and facilitate initiating and maintaining smoking behaviour. By identifying these discourses, health promotion practitioners will be in a position to relate to smokers in a more meaningful and productive way.

\section{METHOD}

\section{Design}

A Q-Methodological design was used, comprising a Q-pack of 60 statements, sorted from -5 to +5 (see table one below). 
Forty-seven female and 48 male undergraduates, aged 18-54 (mean 26 years, sd 9) were recruited from a UK University. In terms of ethnicity, the p-sample comprised 1 Black African, 1 Black Caribbean, 17 Indian, 5 Pakistani, 69 white, 2 mixed-race, and 1 Black English person.

The participants smoking behaviour was classified as being either current smokers $(n=50)$, ex-smokers $(n=18)$ or non/never smokers $(n=27)$, based on current and previous levels of smoking, as well as smoking duration and time since quitting (if relevant). Whilst this sampling over-represents current and ex-smokers compared to the proportion of these groups in the general population, it was sensible to ensure that they were oversampled in this way to facilitate meaningful investigation in the diversity of smoking representations in these key groups.

\section{Materials}

The q-pack (the cards to be sorted) comprised 60 statements based on themes outlined in the introduction. These were developed from an analysis of the literature, and piloted on potential participants. The balance of statements across the themes was not equal.

Rather, it reflected the author's impression of the weighting and importance of the themes as emergent in the literature.

The content of the statements followed the following pattern: Coping and Respite (3 statements): Situational factors (1 statement): Peers and friends (8 statements); Addiction (6 statements); Mood manipulation (7 statements); Smoking locus of control (4 statements); Health beliefs (7 statements); Other smoking beliefs (4 statements); Family issues (2 statements); Weight control (2 statements); Image projection (11 statements); Self-identity construction (2 statements); Social norms (3 statements); Social/Personal 
skills $(1 \text { statement })^{1}$. Alternative versions of the pack were produced in which the tenses and grammar were subtly altered for current, ex-, and never/non smokers to make the statements meaningful for them.

\section{Procedure}

After recording demographic and smoking details, participants were asked to carefully read through all of the statements once. They then sorted them into three piles, approximating to statements they agreed with, disagreed with, or about which they had no strong opinion. From the first pile of statements participants selected the three that they most agreed with, and placed these cards in the right hand column of their sorting grid (the +5 column). They then selected four remaining statements they most agreed with, and put these in the +4 column, and so on until they had placed all of the cards that they agreed with. The process was then repeated, but filling in the grid from the opposite end with the statements that the participant least agreed with. The remaining pile was then used to fill in the centre columns of the sorting grid.

\section{RESULTS}

Data were entered into the MCQ computer package and subjected to a q-methodological analysis. Principle components factor analysis and varimax rotation of the factors was used.

\section{Rationale for Choice of Four Factor Model}

An examination of the unrotated factor matrix indicates that more than eight factors had eigen values above the normal cut off point of 1.0. Eight factors would be both difficult to

\footnotetext{
${ }^{1}$ The full Q-Pack is available from the corresponding author.
} 
interpret, and further, be unlikely to have sufficient people loading on each factor for the factors to be robust. Consequently, four factors were chosen on the basis of a visual examination of the scree plot, which showed a clear 'step' at factor four.

\section{Distribution of Participants Across Factors}

Participants were flagged as loading on factors using the automatic criteria in the MCQ programme. Non-flagged participants were then associated with factors if the loading was greater than 0.3. All participants were subsequently associated with at least one factor. Eighty-five were associated with only one factor, nine with two, and one with three factors. Frequencies of loadings are shown in table two below. The raw figures are somewhat misleading, as there were different numbers in each of the three groups. Percentages of the three sub-samples associated with each factor are also shown in table two.

\section{INSERT TABLE TWO ABOUT HERE}

There were a few participants loading on more than one factor. However, at this stage it is most useful to examine how many participants loaded on each factor regardless of whether they also loaded on other factors. The raw frequencies, along with the percentage calculations for this are shown in table three below.

\section{INSERT TABLE THREE ABOUT HERE}

\section{Interpretation of Factors}

The following section comprises an overview and summary of the content of each of the four factors. A name is given to each factor in the summaries, for convenience rather than an act of deliberate reductionism. This is followed by a comparison of the four factors, 
investigating the differences between them. Illustrations of the most extreme statements associated with these factors are provided, but the interpretation is made on the basis of the whole sort.

\section{Factor One}

\section{Statements Most Agreed With}

$+5$

I am probably doing real damage to my health through smoking

I regret starting smoking

Passive smoking from cigarettes harms non-smokers

$+4$

If I go without cigarettes, I have cravings to smoke

When I am feeling stressed, a cigarette helps me feel better

I find smoking relaxing

I am physically dependent on getting nicotine into my bloodstream

A way of taking a break for me

\section{Statements Most Disagreed With} $-5$

It is unlikely that smoking will, in reality, do me personal harm Smoking makes me look cooler

There would not be any strong health benefits to my quitting

$-4$

The dangers of smoking are over-emphasised

I look sexier when I smoke

I look sophisticated when I smoke

I do smoke, but am not addicted to smoking 
Summary. Factor one reflects concern about damage to physical health, and views smoking as an addictive behaviour. Those in this factor can be summarised as being Independent Addicts who oppose smoking imagery. They reject any positive imagery associated with smoking, such as being sophisticated or sexy. Two items taken from the locus of control scale reflecting external locus of control are strongly disagreed with which may reflect a sense of individual/personal responsibility for smoking.

Factor Two

Statements Most Agreed With

$+5$

Smoking is my own choice - I am not the victim of pressure from anyone

I am probably doing real damage to my health through smoking

When I feel stressed, a cigarette helps me feel better

$+4$

I am in control of whether I smoke or not

Passive smoking from cigarettes harms non-smokers

I find smoking relaxing

I do smoke, but am not addicted to smoking

\section{Statements Most Disagreed With}

$-5$

If I didn't smoke I would lose friends

Smoking makes me look vain or arrogant

I have felt pressure from my peers that I ought to smoke

$-4$

Smoking signals to other people that I am an independent person

If I smoke, people see me as more unhappy or depressed

If I smoke, people are more likely to think I am hard or tough

Smoking helps me look more like an adult and less like a child 
Summary. Factor two is also associated with a belief that smoking causes health damage. However, there is a clear message from these participants that they do not present themselves as smoking addicts, and their smoking is not caused by peer pressure. Rather, smoking is seen to be an autonomous choice, which is normalised, and a function of mood control. Notably, 'positive' images associated with smoking (adult - tough independent) are the most rejected. These smokers are perhaps best seen as Independent non-addicts

Factor Three

Statements Most Agreed With $+5$

I am probably doing real damage to my health through smoking

Passive smoking from cigarettes harms non-smokers

I regret starting smoking

$+4$

Smoking is my own choice - I am not a victim of peer pressure from anyone

I am in control of whether I smoke or not

I saw my parents/guardians smoking when I was growing up

Smoking makes me look vain or arrogant

\section{Statements Most Disagreed With} $-5$

Smoke from cigarettes tastes good

I smoke to relieve boredom

Smoking is a way of taking a break for me 
When I am angry I smoke

Smoking gives me real pleasure

I smoke when I am depressed

When I smoke, I look more confident

Summary. This factor also accepts the notion of health damage caused by smoking, but argue for being in control of smoking ( $\&$ reject peer influence), and oppose positive features of smoking (taste, structuring activities, $\&$ mood control). This factor represents the Anti-smoker: Non-addict who views smoking as negative with negative vicarious experiences?

\section{Factor Four}

\section{Statements Most Agreed With}

$+5$

Smoking marks me out as belonging to a certain social group

I am probably doing real damage to my health through smoking

My peers generally approve of smoking

$+4$

I feel more accepted and part of a crowd when I smoke

It is not unusual to smoke

Smoking is really a very common behaviour

For me, smoking a cigarette is like a drug addiction

\section{Statements Most Disagreed With}

$-5$

Smoking gives me real pleasure

My siblings (brothers/sisters) smoke

Smoke from cigarettes tastes good 
$-4$

I saw my parent/guardian(s) smoke when I was growing up

If don't stop, because don't get help (external locus)

Everything unhealthy now - smoking no different

I look sexier when I am smoking

Summary. This factor represents a view of social smoking, with smoking being normalised. They disagree with intrinsic (non-social) benefits of the pleasure/taste of cigarettes, and are unlikely to report family smoking. Despite placing their smoking in such a social arena, these smokers do not adopt an external locus. These might be classed as Socially addicted smokers- whose smoking is normalised and functional-possibly with a sense of smoking as an addiction

\section{DISCUSSION}

This study is different from other Q-methodological studies (e.g., Collins, Maguire \& O’Dell, 2002), because as well as exploring potential diversity within smokers, it examined the extent to which the use of particular explanations of smoking differentiated smokers, never-smokers, and ex-smokers, to understand the existing and potential role for health promotion in smoking cessation. Contrary to many qualitative analyses of smoking there was also no intention to identify 'themes' that are associated with smoking and can be applied (to a greater or lesser degree) to all participants. Instead, the factors discussed reflect focal points in a continuum of meanings relating to smoking, which are the product of shared, subjective discourses about smoking. These factors may or may not be accessed and used by any particular participant, or indeed wider society.

Four factors were chosen to describe the structure of the 95 participants discourse, and these were given the (oversimplified) labels of 'independent addict', 'independent non-addict,' 'anti-smoker' and 'social addict'. Although the distribution of neversmokers, current smokers, and ex-smokers was of interest to this study, it would be a 
mistake to claim that particular factors were associated with particular stage of smoking behaviour. However, the broad trend is worth commenting on. Smokers primarily loaded upon the first two factors - independent addicts and independent non-addicts. Neversmokers were distributed across the four factors, but notably, factor four was almost exclusively made up of never-smokers. The few smokers who did load (partially) on this factor did so in a negative way, suggesting an explicit rejection of the values proposed within it. Factor three was an even more extreme example of this pattern as a third of the number of never-smokers loaded on this factor, with only one current smoker and no exsmokers contributing to this factor. More than half of the ex-smokers loaded on factor two (affect regulation). They also had a noteworthy representation on factor one. In many respects, the current and ex-smokers sorted in similar ways to each other, the main difference being a shift to affect regulation and away from independent addiction in the ex-smokers.

There are at least three important implications of this pattern of results. Firstly, current, non- and ex-smokers do not form three homogeneous, distinct groups who use their own patterns of talk about smoking, as there is a degree of shared discourse. Secondly, never-smokers, differ in their 'under' emphasis on the affect regulation function of smoking, and their construction of the anti-smoker factor. The third implication is the broad similarity and subtle difference across the current and ex-smokers, as they comprised factors one (independent addicts) and two (independent non-addicts), and there was a shift away from independent addiction and towards affect regulation in the exsmokers. These findings suggest that never-smokers often talk about smoking in quite a different way to current and ex-smokers. It is possible that smokers who are more likely to use factor two (independent non-addict) discourse are more able to give up - possibly feeling less trapped by a construction of smoking as an addiction from which they cannot 
escape. Alternatively, it is possible that ex-smokers are likely to retrospectively reconstruct their earlier smoking behaviour in a way that is consistent with their successful quit attempts, rather than independent addiction.

An implication of this work is that we may need to move smokers not to the discourse of never-smokers (which seems at odds with that of ex-smokers), but to the discourse of ex-smokers. Current attempts in health promotion to perpetuate a representation of smokers as suggested in factors three and four is likely to be rejected, and fail. This approach ignores the fact that ex-smokers have a special knowledge and experience of smoking, which is at odds with the perspectives of factors three and four. To try and move them to using these representations would be unrealistic and condemned to fail. However, we may need to take a different view, with never-smokers, as it is possible that they use smoking discourse with no concern at all for smokers. Consequently, using factors three and four could be reinforcing their own position that they are the superior party (i.e. more worthy or morally acceptable).

\section{Analysis and Discussion of the Factors}

It is both notable and very important that all factors include the statement 'I am probably doing real damage to my health through smoking' in the +5 position, and other health related statements are scored highly across all the factors. This suggests that the money and effort put into health promotion and public messages about the dangers of smoking has had the desired effect - to be heard and accepted, as there is consensus that smoking is a dangerous activity. However, it is clear that understanding the health risk plays no part in determining wider social representation of smoking, and no longer serves a key function in the process of ceasing to be a smoker. Any health promotion strategy based around attempting to inform people about the health dangers of smoking is of little value. 
This finding alone makes the study worthwhile, and reinforces the rationale to look at the wider contextual rationales provided by participants, that may serve to differentiate those of different smoking status.

\section{Factor One Independent Addict}

Factor one is characterised by a largely negative view of smoking, with ideas of the smoker as an addict being central. The notion of regret at starting smoking $(+5)$ is consistent with a negative view, and the impression of the function of smoking is very much around controlling dependence on cigarettes. The concept of this factor reflecting 'independent' addiction arises from the generally individualistic reasons given for smoking, and the explicit rejection of the 'image projection' functions of smoking. There is also a rejection of two items from the smoking locus of control scale that were included as statements ("If I fail in attempts to stop smoking, I wasn't meant to be a never-smoker" and "If I don't stop smoking it is because I don't get the help I need"). This further reinforces the idea that this factor represents an individual, rather than social, model of smoking. There is also a theme of affect regulation within this account of smoking (which is what would be expected of an account based around managing addictive symptomatology), and there is a strong correlation $(\mathrm{r}=0.6)$ between this factor and factor two, with the primary difference being the extent to which addiction is accepted. Consequently, to work with this account of smoking, health professionals would need to focus on empowering individuals who perceive themselves as addicted.

\section{Factor Two Independent Non-Addicts}

The predominant themes in factor two are affect control, and a rejection of the notion of addiction. Participants responded in a way highly consistent with some of the suggestions 
of Denscombe (2001a), in their rejection of the role of peers in smoking, and in their claims for the agency of their smoking ("Smoking is my own choice - I am not the victim of pressure from anyone", +5 ; "I have felt pressure from my friends that I ought to smoke", -5). Smoking is normalised, and used as a means of controlling daily mood (feeling stressed, depressed, \& as a means of relaxation). Again, there is a rejection of notions of smoking being a mechanism of image and identity management.

This factor is similar to factor one, with the clear difference being the extent to which factor two implies an outright rejection of the notion of being addicted. This presents the health professional with a paradox. Unless a smoker can work with the notion of addiction, they may not be able to anticipate or cope with withdrawal symptoms and cravings. This lack of feeling trapped by smoking may serve to encourage the smoker to procrastinate and persist in smoking, on the basis that it could be stopped any time - but why right now? Having worked with the notion of addiction, it would then be necessary, as with factor one, to teach alternative means of affect management. This account of smoking is reminiscent of the findings of Mayhew et al. (2000), who found that accounts of smoking for affect control emerge at early stages of smoking.

\section{Factor Three: The anti-smoker}

This factor was almost entirely a product of the sorts of never-smokers. Given that the participants are presenting a received view of smoking, and not describing personal experience or even acting to present their own smoking behaviour in a particular light this therefore reflects a non-experiential discourse about smoking. The source of this received view perhaps represents most clearly the traditional agenda of the health educator. Unsurprisingly, given its constituent members are not smokers, there is a rejection of the notion of being addicted to cigarettes, and like the other factors negative health messages 
associated with smoking are to the fore. However, the negative images attached to smoking elsewhere in the literature (see introduction) appear here; smoking is vain/arrogant, dirty and smelly, and they reject or fail to recognise any of the positive features of smoking as experienced by smokers - in particular, that of mood regulation. Family smoking is also reported negatively, suggesting these participants have experienced smoking 'second hand', and found it wholly objectionable.

The implications for health promotion are twofold. Firstly, the lack of empathy may alienate smokers on the receiving end of 'helpful' advice from never-smokers. Secondly, it is clear that although the negative imagery associated with smoking is well understood by those in factor three, this is not widely shared, so although the health message from health promoters has been heard and believed, they may not have been heeded.

\section{Factor Four: The Social Addict}

This factor places smoking in a broad social context, and again was largely comprised of never-smokers, and those smokers who do load on the factor do so negatively - indicating a polar opposition to it. One possibility as to why this factor is largely comprised of never-smokers is that it represents an inaccurate stereotype of a certain kind of smoker, perpetuated as a myth amongst never-smokers. This would warrant further investigation, to ascertain whether the use of this kind of discourse allows never-smokers to avoid becoming smokers. It is also possible that these participants, not having any stake in presenting smoking in any particular positive or negative light, are describing the behaviour of some smokers in a way which the smokers themselves would feel uncomfortable doing. 
A direct examination of the content of the factor shows that as well as differences in the social functions of smoking, the emphasis on positive image projection also differentiates this factor from each of the other three. This suggests that the participants in factor four are describing a conformist, socially functional view of smoking that is rejected by smokers themselves. The prevailing discourse amongst smokers is of autonomy, personal agency, and freedom of choice (Denscombe, 2001b). If there were a group of smokers who were smoking to be cool, sophisticated, etc., it would be very difficult for this to emerge in their own Q-sort. There is nothing so guaranteed to undermine an attempt to be cool as admitting the attempt. This suggests a rhetorical account of smoking in which smokers could not admit the social function of their smoking - an issue at odds with 'objective' data.

On personal agency, addiction, and self-regulation While it is beyond the scope of this paper to engage in a detailed analysis of the concept and label of addiction, it is clearly pertinent to briefly consider the meanings of addiction.

That smoking is 'addictive' is taken in the medical literature, and almost all of the social science literature, as a given. However, of the four accounts of smoking provided here, only the first clearly associated smoking with addiction, with little reference in factors two and three, and only limited association with addiction in factor four. The dilemma as to whether it is helpful for smokers to consider themselves an addict has been mentioned above (in the analysis of the factors). By claiming they smoke due to addictive forces seemingly beyond their control (such as biochemical agents, spontaneous cravings, \& so on), places themselves in a position of powerless, helpless victims, making it difficult for them to identify or consider wider social resources as relevant to overcoming their smoking. On the other hand, if social accounts of smoking place blame for the 
addiction in wider society, the smoker may accept the power of social forces, but feel disempowered to act. Consequently, a more helpful discourse would be a concept similar to Radley's (1994) notion of the embodied self, where the benefits of smoking are replaced, using a discourse of strength and vitality.

\section{Tailored Health Promotion}

The suggestion in this study is that this Q-analysis should inform health promotion, through actively changing the discourses that are used by individuals to account for, warrant, and legitimise their smoking behaviour. Historically, this would have been impossible. Health communication around smoking has followed a generic approach that actively attempted to create a particular social representation of smoking, a negative stereotype of the smoker not dissimilar to factor three in this study. There has been little acknowledgement of either the rationales provided by smokers (such as actively choosing to smoke, rather than being 'peer pressured' into it), or the fact that smokers are not a homogenous group, differing only on demographic characteristics, and the amount and duration of their smoking habit.

More recently, mechanisms have been developed to at least tackle the second of these problems - that is, to move away from generic health messages to more diverse tailored messages carrying the health promotion message, recognising individual differences (see, for example, the review by Lancaster, Stead, Silagy \& Sowden, 2000). Though it is tempting to suggest that the factors reported in this study could be used as the basis of such an intervention, the lack of claimed generalisability in Q-methodological work precludes this approach. Instead of focussing upon working with individual smokers, or designing mass mailings of health messages more effectively, it is hoped that instead, the reader will begin to think about the way in which smoking - and health 
promotion around smoking - has largely failed to work with the subjective meanings of smoking for smokers and never-smokers. The findings of the work clearly demonstrate the functional aspects of smoking for smokers - predominantly around affect control. In addition to considering interventions aimed at smokers managing affect differently, an alternative question that might be asked is how society produces such widely reported negative states? By providing an acceptable, describable response to negative mood, stress, anger and boredom, to what extent does smoking serve a wider social function of legitimising social structures that elicit these responses? Given the huge social inequalities in smoking and the resulting smoking related disease (Bridgewood, Lilly, Thomas, Bacon, Sykes, \& Morris, 2000), issues of social structure and power are crucial. Further work is needed to explore this idea in more depth, but the emphasis must be shifted from the individual smoker to the forces that create the social world in which the smoker lives as the production of subjective meanings around smoking behaviour should have a more radical purpose than simply adapting pre-existing health promotion paradigms to accommodate further individualistic interventions.

\section{CONCLUSION}

The study examined the structure and meanings associated with four Q-factors. It is suggested that there are not necessarily profound differences between the representations of current and ex-smokers. Some of the never-smokers, however, did produce factors that were almost orthogonal to the current and ex-smokers perspectives. This suggests that either never-smokers use protective discourses about smoking to which the current and ex smokers do not have access, (in which case, the extent to which these factors are more widely represented and functional should be investigated), or that never-smokers have nothing to lose in portraying smokers in a negative (factor three) or superficial (factor 
four) light. The division between factors one and two was also interesting. The most significant difference was the sense of addiction described by factor one, and the sense of autonomy and rejection of addiction in factor two. There are clearly implications for health promoters in understanding and further unpacking the consequences of the use of these perspectives. Above all, it is hoped that this work serves to place an understanding of smoking in a social and discursive realm, where smokers and never-smokers are seen as something other than the embodiment of a collection of social-cognitive variables. 


\section{REFERENCES}

Allbutt, H., Amos, A., \& Cunningham-Burley, S. (1995). The social image of smoking among young people in Scotland. Health Education Research, 10, 443-454.

Amos, A., Wiltshire, S., Haw, S., \& McNeill, A. (2006). Ambivalence and uncertainty: experiences of and attitudes towards addiction and smoking cessation in the midto-late teens. Health Education Research, 21, 181-191.

Austin, S. B., \& Gortmaker, S. L. (2001). Dieting and smoking initiation in early adolescent girls and boys: A prospective study. American Journal of Public Health, 91, 446-450.

Breteler, M. H. M., Schotborg, E. J., \& Schippers, G. M. (1996). The effectiveness of smoking cessation programs: Determinants and outcomes. Psychology and Health, 11, 133-153.

Bridgewood, A., Lilly, R., Thomas, M., Bacon, J., Sykes, W., \& Morris, S. (2000). Office for National Statistics. Living in Britain: Results from the 1998 General Household Survey. London, Stationary Office.

Brown, J. M. (1996). Redefining Smoking and the Self as a nonsmoker. Western Journal of Nursing Research, 18, 414-428.

Chamberlain, K., \& O'Neill, D. (1998). Understanding social class differences in health: A qualitative analysis of smokers health beliefs. Psychology \& Health, 13, 11051119.

Clayton, S. (1991). Gender differences in psychosocial determinants of adolescent smoking. Journal of School Health, 61, 115-120.

Collins, P., Maguire, M., \& O’Dell, L. (2002) Smokers' Representations of their own Smoking: A Q-methodological study. Journal of Health Psychology, 7, 641-652. 
Denscombe, M. (2001a). Peer group pressure, young people and smoking: New developments and policy implications. Drugs Education Prevention \& Policy, 8, 732.

Denscombe, M. (2001b). Uncertain identities and health-risking behaviour: the case of young people and smoking in late modernity. British Journal of Sociology, 52, 157-177.

Department of Health (1998). Smoking Kills: A white paper on tobacco. London, Stationary Office.

Fiissel, D.L., \& Lafreniere, K. D. (2006). Weight control motives for cigarette smoking: Further consequences of the sexual objectification of women? Feminism \& psychology, 16, 327-344.

Georgiou, A. \& Bradley, C. (1992). The development of a smoking-specific locus of control scale. Psychology \& Health, 6, 227-246.

Gillard, J., \& Bruchton-Schweiter, M. (2001). Development and validation of a multidimensional smoking behaviour questionnaire. Psychological Reports, 89, 499-509.

Gillies, V. \& Willig, C. (1997). You get the nicotine and that in your blood - Constructs of addiction and control in woman's accounts of cigarette smoking. Journal of Community and Applied Social Psychology, 7, 285-301.

Glantz, S. A. \& Jamieson, P. (2000). Attitudes toward secondhand smoke, smoking, and quitting among young people. Pediatrics, 16, U42-U44.

Gleeson, K. (1991). Out of our minds: The deconstruction and reconstruction of madness. Unpublished PhD Thesis, University of Reading.

Graham, H. (1987). Women's smoking and family health. Social Science \& Medicine, 25, $47-56$. 
Hollway, W. (1989). Subjectivity and Method in Psychology: Gender, Meaning and Science, London, Sage.

Lancaster, T., Stead, L., Silagy, C., \& Sowden, A. (2000). Effectiveness of interventions to help people stop smoking. Findings from the Cochrane library. British Medical Journal, 321, 355-358.

Lennon, A., Gallois, C., Owen., N., \& McDermott, L. (2005). Young women as smokers and nonsmokers: A qualitative social identity approach. Qualitative Health Research, 15, 1345-1359.

Lyna P., McBride C., Samsa, G., \& Pollak, K. (2002). Exploring the association between perceived risks of smoking and benefits to quitting. Who does not see the link? Addictive behaviors, 27, 293-307.

Mayhew, K. P., Flay, B. R., \& Mott, J. A. (2000). Stages in the development of adolescent smoking. Drug and Alcohol Dependence, 59, S61-S81.

McKie, L., Laurier, E., Taylor, R. J., \& Lennox, A. S. (2003). Eliciting the smoker's agenda: implications for policy and practice. Social Science \& Medicine, 56, 8394.

Michel, L. \& Amos, A. (1997). Girls, pecking order and smoking. Social Science \& Medicine, 44, 1861-1869.

Moffat, B. M. \& Johnson, J. L. (2001). Through the haze of cigarettes: teenage girls' stories about cigarette addiction. Qualitative Health Research, 11, 179-189.

Morgan, M. \& Grube, J. W. (1989). Adolescent cigarette smoking: A developmental analysis of influences. British Journal of Developmental Smoking, 7, 179-189.

Moscovici, S. (1976). Social Influence and Social Change. Academic Press

Ltd., London, UK. 
Radley, A. (1994). Making sense of illness: The social psychology of health and disease. Sage, London .

Rotter, J.B. (1966) Generalised expectancies for internal vs external control of reinforcement. Psychological monographs, 80, (whole no. 609).

Rugkasa, J., Knox, B., Sittlington, J., Kennedy, O., Treacy, M. P., \& Abaunza, P. S. (2001). Anxious adults vs. cool children: children's views on smoking and addiction. Social Science \& Medicine; 53, 593-602.

Seguire, M. \& Chalmers, K. I. (2000). Late adolescent female smoking. Journal of Advanced Nursing, 31, 1422-1429.

Sontag, S. (1977). Illness as Metaphor. Farrar, Straus, and Giroux, New York.

Sontag, S. (1989). AIDS and its metaphors. Allan Lane, London.

Stephenson, W. (1935) Technique of factor analysis. Nature, 136, 297.

Stewart, C. (1999). Investigation of cigarette smokers who quit without treatment. Journal of Drugs Issues, 29, 167-185.

Stewart, M.J., Brosky, G., Gillis, A., Jackson, S., Johnston, G., Kirkland, S., Leigh, G. Pawliw-Fry, B. A., Persaud, V. \& Rootman, I. (1996). Disadvantaged women and smoking. Canadian Journal of Public Health, 87, 257-60.

Stewart-Knox, B. J., Sittlington, J., Rugkasa, J., Harrisson, S., Treacy, M. \& Abaunza, P. S. (2005). Smoking and peer groups: Results from a longitudinal qualitative study of young people in Northern Ireland. British Journal of Social Psychology, 44, $397-414$

Unger, J. B., Rohrbach, L. A., Howard-Pitney, P., Ritt-Olson, A., \& Mouttapa, M. (2001). Peer influences and susceptibility to smoking among California adolescents. Substance Use and Misuse, 36, 551-571. 
Wiltshire, S., Amos, A., Haw, S. \& McNeill, A (2005). Image, context and transition: smoking in mid-to-late adolescence. Journal of Adolescence, 28, 603-617.

Zucker, A. N., Stewart, A. J., Pomerleau, C. S. \& Boyd, C. J. (2005). Resisting gendered smoking pressures: Critical consciousness as a correlate of women's smoking status. Sex Roles, 53, 261-272. 
ACKNOWLEDGEMENTS:

The authors would like to thank Dr Kate Gleeson and Dr Simon Murphy for comments on an earlier draft of this paper, and helpful discussions in design phase of the work. 
Table 1

Frequency of cards across the sorting grid

\begin{tabular}{|l|l|l|l|l|l|l|l|l|l|l|l|}
\hline $\begin{array}{l}\text { Number of } \\
\text { cards }\end{array}$ & 3 & 4 & 6 & 6 & 7 & 8 & 7 & 6 & 6 & 4 & 3 \\
\hline $\begin{array}{l}\text { Score for } \\
\text { cards }\end{array}$ & -5 & -4 & -3 & -2 & -1 & 0 & 1 & 2 & 3 & 4 & 5 \\
\hline
\end{tabular}

Participants (p-sample) 
Table 2

Frequency of participant loadings on factors

\begin{tabular}{|r|c|c|c|c|c|c|c|c|}
\hline \multirow{2}{*}{ FACTOR } & \multicolumn{2}{|c|}{ Smokers } & \multicolumn{2}{c|}{ Never-smokers } & \multicolumn{2}{c|}{ Ex-smokers } & \multicolumn{2}{c|}{ TOTAL } \\
\cline { 2 - 9 } & $\mathrm{n}$ & $\%$ & $\mathrm{n}$ & $\%$ & $\mathrm{n}$ & $\%$ & $\mathrm{n}$ & $\%$ \\
\hline F1 only & 22 & 44.0 & 8 & 28.6 & 6 & 33.3 & 36 & 37.9 \\
\hline F2 only & 19 & 38.0 & 4 & 14.3 & 10 & 55.6 & 33 & 34.7 \\
\hline F3 only & 1 & 2.0 & 9 & 32.1 & 0 & 0.0 & 10 & 10.5 \\
\hline F4 only & 1 & 2.0 & 5 & 17.9 & 0 & 0.0 & 6 & 6.3 \\
\hline Factors 1\& 2 & 3 & 6.0 & 1 & 3.6 & 1 & 5.6 & 4 & 4.2 \\
\hline Factors 2 \& 3 & 0 & 0.0 & 1 & 3.6 & 0 & 0.0 & 1 & 1.1 \\
\hline Factors 1\& 4 & 1 & 2.0 & 0 & 0.0 & 0 & 0.0 & 1 & 1.1 \\
\hline $1 \&-4$ & 2 & 4.0 & 0 & 0.0 & 0 & 0.0 & 2 & 2.1 \\
\hline Factors -3 \& 4 & 0 & 0.0 & 0 & 0.0 & 1 & 5.6 & 1 & 1.1 \\
\hline Factors 1 \& 2 \& -4 & 1 & 2.0 & 0 & 0.0 & 0 & 0.0 & 1 & 1.1 \\
\hline None & 0 & 0.0 & 0 & 0.0 & 0 & 0.0 & 0 & 0.0 \\
\hline TOTAL & 50 & 100 & 28 & 100 & 18 & 100 & 95 & 100 \\
\hline
\end{tabular}


Table 3

Frequencies for simplified loading pattern.

\begin{tabular}{|c|c|c|c|c|c|c|}
\hline \multirow{2}{*}{ FACTOR } & \multicolumn{2}{|c|}{ Smokers } & \multicolumn{2}{c|}{ Never smokers } & \multicolumn{2}{c|}{ Ex-smokers } \\
\cline { 2 - 7 } & $\mathrm{n}$ & $\%$ & $\mathrm{n}$ & $\mathrm{n}$ & $\%$ & $\mathrm{n}$ \\
\hline F1 at all & 29 & 51.8 & 9 & 30.0 & 7 & 36.8 \\
\hline F2 at all & 23 & 41.1 & 6 & 20.0 & 11 & 57.9 \\
\hline F3 at all & 1 & 1.8 & 10 & 33.3 & 0 & 0.0 \\
\hline F4 at all & 3 & 5.4 & 5 & 16.7 & 1 & 5.3 \\
\hline TOTAL & 56 & 100 & 30 & 100 & 19 & 100 \\
\hline
\end{tabular}

